\title{
DRIVE IMAGINING
}

I'm speeding west somewhere in the top of Ohio or Indiana,

And to my right is the Arctic Circle, all white and scary.

It is very dark and cold

But my car is very powerful, shut, and too warm.

To my left is super-powerful New Orleans Radio 87,

Beaming girl singers with crooked jaws.

I test you by asking the time but

You trust me to not give you the wheel while you're sleeping.

Your mouth is like the curve of the earth for fifty miles on flat ice.

Out loud, unevenly, I say where the road right goes. No answer.

Your skirt is high and little,

Filling the front of the car with pounds of white.

My nails raise the flesh there;

Electricity from the big dots and standing hair sends the radio signal Into a trough. Eyes shut, you are awake

Enough to say, I can't breathe, fix the heat.

You sigh and lean back like a snowflake pressing into a marshmallow.

The urge to ask your advice about the possible right turn

To Sault Ste Marie, Canada, and you-know-where

Is a malignant lump in my chest, like facing the dark makes.

And at what point would we drive out onto the nothing but ice?

Cresting she says, Hello truck drivers,

And mentions a more powerful flashlight for them to buy.

That's the trouble with global capabilities,

You can be fighting icebergs and some joker will yell

In your ear, Hello I'm Johnny Cash.

I shout that the road right goes you-know-where.

Eyes shut, you are awake enough to say,

All that's stopping us is a lack of gas stations,

My twisted mouth around your fear. 